\title{
Malic Enzyme Activity in Bacteroids from Soybean Nodules
}

\author{
By LES COPELAND, ${ }^{1 *}$ ROSANNE G. QUINNELL ${ }^{2}$ AND DAVID A. DAY \\ ${ }^{1}$ Department of Agricultural Chemistry, The University of Sydney, NSW 2006, Australia \\ ${ }^{2}$ Botany Department, Australian National University, Canberra, ACT 2601, Australia
}

(Received 15 November 1988; revised 1 March 1989; accepted 10 April 1989)

\begin{abstract}
Soluble extracts of Bradyrhizobium japonicum bacteroids from soybean root nodules showed substantial rates of $\mathrm{NAD}^{+}$and $\mathrm{NADP}^{+}$reduction which were malate and $\mathrm{MnCl}_{2}$ dependent. Pyruvate was formed stoichiometrically and the NAD- and NADP-dependent rates were additive, indicating the presence of two malic enzymes. The NADP-dependent malic enzyme had a high affinity for malate (apparent $K_{\mathrm{m}}=0.1 \mathrm{mM}$ ) and was stimulated by ammonium. The NAD-dependent malic enzyme had a lower affinity for malate (apparent $K_{\mathrm{m}}=1.9 \mathrm{~mm}$ ) and was stimulated by potassium and ammonium salts. The maximum velocities of the two enzymes were similar and of comparable magnitude to the activities of tricarboxylic acid cycle enzymes in the extracts. Possible roles of the malic enzymes in the metabolism of malate and succinate in bacteroids are discussed.
\end{abstract}

\section{INTRODUCTION}

Transport and metabolism of dicarboxylic $\mathrm{C}_{4}$-organic acids are essential for the development of nitrogen-fixing bacteroids in legume root nodules (Finan et al., 1981; Ronson et al., 1981; Arwas et al., 1985). These acids support nitrogen fixation by isolated bacteroids (Appleby, 1984) and are present in high concentrations in legume nodules (Stumpf \& Burris, 1979). Furthermore, succinate, fumarate and malate are readily transported across the peribacteroid membrane which encloses the bacteroids in vivo (Price et al., 1987; Udvardi et al., 1988), and it is generally considered that succinate or malate are the most likely forms of carbon supplied by the plant to support nitrogen fixation (Appleby, 1984; Dilworth \& Glenn, 1984).

Although a key role for these organic acids in nitrogen fixation has been established, the details of their metabolism by bacteroids have not been elucidated. The existence of a functional tricarboxylic acid (TCA) cycle in Rhizobium and Bradyrhizobium species has been demonstrated (Storvall \& Cole, 1978; Karr et al., 1984; Appleby, 1984) but these studies have not demonstrated how imported malate and succinate are metabolized. Gluconeogenic enzymes are present in Rhizobium leguminosarum bacteroids (McKay et al., 1985) and may be involved in organic acid metabolism. In Bradyrhizobium japonicum bacteroids, added malate and succinate are converted to glutamate in long-term incubations (Salminen \& Streeter, 1987) but the pathways involved have not been identified.

Malic enzyme (ME), in combination with malate dehydrogenase (MDH), provides a very efficient way of metabolizing added malate (or succinate) since both pyruvate and oxaloacetate (OAA) are provided to the TCA cycle. Such a pathway, involving an NAD-linked ME (EC 1.1.1.38), operates in plant mitochondria (Day \& Hanson, 1977). Escherichia coli possesses both an NAD- and an NADP-linked ME (EC 1.1.1 .40) which are thought to be involved in malate catabolism and generation of reducing power (Murai et al., 1971; Hansen \& Juni, 1975). Recently, NAD- and NADP-dependent ME activities have been demonstrated in $R$. leguminosarum (MacKay et al., 1988), but whether these were due to one or two enzymes was not 
determined. There have been no reports to date of ME activity in Bradyrhizobia. In this paper we describe an investigation of $\mathrm{ME}$ in $B$. japonicum bacteroids isolated from soybean nodules. Evidence is presented which indicates the occurrence of separate NAD- and NADP-dependent enzymes. The possible role of these enzymes is discussed in terms of bacteroid metabolism and nitrogen fixation.

\section{METHODS}

Materials. Seeds of soybean [Glycine $\max$ (L.) Merr.] cv. Bragg were inoculated with B. japonicum strain USDA 110 and grown in pots in a glasshouse, as described previously (Day et al., 1987). Nodules were harvested from plants two to three months old.

Preparation of extracts. All steps were carried out at $4{ }^{\circ} \mathrm{C}$. Bacteroids were isolated from $10-15 \mathrm{~g}$ of nodules and purified by centrifugation in a Percoll density gradient as described previously (Day et al., 1986). Purified bacteroids were resuspended in $6 \mathrm{ml} 25 \mathrm{mM}$-TES/NaOH buffer (pH 7.5) which contained $50 \mathrm{mM}-\mathrm{KCl}, 5 \mathrm{~mm}-$ $\mathrm{MgSO}_{4}$ and $5 \mathrm{mM}$-DTT and the soluble extract prepared by passing the suspension three times through a Yeda press at $14000 \mathrm{~Pa}$. The broken bacteroids were centrifuged at $100000 \mathrm{~g}$ for $1 \mathrm{~h}$ and the supernatant used for assays. Solid $\left(\mathrm{NH}_{4}\right)_{2} \mathrm{SO}_{4}$ was used to fractionate crude bacteroid extracts. Pellets were redissolved in the same buffer used to resuspend the bacteroids.

Assay of enzymes. All enzyme assays were carried out at $25^{\circ} \mathrm{C}$. Malic enzyme activity was assayed by measuring the increase in $A_{340}$ due to the formation of NADH or NADPH. Standard reaction mixtures contained, in a volume of $1 \mathrm{ml}, 50 \mathrm{~mm}-\mathrm{HEPES} / \mathrm{NaOH}$ buffer (pH 7), $20 \mathrm{mM}-\mathrm{KCl}, 0.75 \mathrm{mM}-\mathrm{EDTA}, 5 \mathrm{~mm}-\mathrm{L}$-malate, $1 \mathrm{mM}-\mathrm{NAD}^{+}$ or $\mathrm{NADP}^{+}, 6 \mathrm{mM}-\mathrm{MnCl}_{2}$ and an appropriate volume of bacteroid extract. In experiments where the formation of pyruvate was measured, reactions were stopped by the addition of $0.1 \mathrm{ml}$ of $1 \mathrm{M}-\mathrm{HCl}$ and the precipitate removed by centrifugation. Pyruvate in the supernatant was determined spectrophotometrically as described by Wedding et al. (1976).

3-Hydroxybutyrate dehydrogenase activity was assayed in reaction mixtures which contained, in a volume of $1 \mathrm{ml}, 50 \mathrm{~mm}$-HEPES/ NaOH buffer (pH 7), $10 \mathrm{mM}$-acetoacetate, $0.2 \mathrm{mM}-\mathrm{NADH}$ and an appropriate volume of bacteroid extract. Isocitrate, malate and pyruvate dehydrogenase activities were measured as described by Karr $e t$ al. (1984), except that $50 \mathrm{mM}-\mathrm{HEPES} / \mathrm{NaOH}$ buffer $(\mathrm{pH} 7)$ was used in the reaction mixtures. Protein was determined by the Lowry method, using bovine serum albumin as standard.

The oxidation of NADH and NADPH by B. japonicum extracts was determined after bacteroids had been sonicated for three $1 \mathrm{~min}$ periods at $100 \mathrm{~W}$. The sonicate was centrifuged at $14000 \mathrm{~g}$ for $2 \mathrm{~min}$ and the supernatant used to measure $\mathrm{O}_{2}$ uptake as described by Day et al. (1986).

\section{RESULTS}

Solubilized extracts of soybean bacteroids displayed substantial rates of $\mathrm{Mn}^{2+}$-dependent $\mathrm{NAD}^{+}$and NADP ${ }^{+}$reduction in the presence of malate (Figs 1 and 2 ). This reduction was a linear function of the quantity of soluble protein added to the reaction mixtures and was accompanied by the production of stoichiometric quantities of pyruvate (Fig. 1). Addition of $\mathrm{NADP}^{+}$to a reaction mixture containing $\mathrm{NAD}^{+}$caused a rate of increase in $A_{340}$ exactly equivalent to the rate of reduction of $\mathrm{NADP}^{+}$alone (Fig. 2), indicating that the rates of $\mathrm{NAD}^{+}$ and $\mathrm{NADP}^{+}$reduction were additive.

These results suggest that soybean bacteroids contain both an NADP- and an NAD-linked ME. However, since the bacteroid extract also contains high NAD-dependent MDH activity and can catalyse considerable OAA decarboxylation in the presence of $\mathrm{MnCl}_{2}(\mathrm{Table} 1)$, caution must be exercised when interpreting the data for $\mathrm{NAD}^{+}$reduction. $\mathrm{MDH}$ coupled to OAA decarboxylation could also lead to stoichiometric formation of NADH and pyruvate. We think it unlikely that NAD-ME activity was due to the presence of MDH for the following reasons. (1) NAD-ME was stimulated by $\mathrm{KCl} ; \mathrm{MDH}$ and OAA decarboxylation were not (Table 1). (2) Desalting the bacteroid extract had little effect on MDH activity, stimulated OAA decarboxylation, but inhibited NAD-ME (Table 1). (3) Addition to the reaction medium of a quantity of commercial (rabbit muscle) NAD-MDH equivalent to the amount of MDH activity in the bacteroid extract stimulated ME activity by less than $10 \%$. If pyruvate formation were due to $\mathrm{MDH}$ in conjunction with OAA decarboxylation, a doubling of the activity should have resulted. (OAA decarboxylation was not rate-limiting.) (4) NAD-ME was very labile after freezing and thawing the bacteroid extract, sometimes losing all activity; yet MDH and OAA 


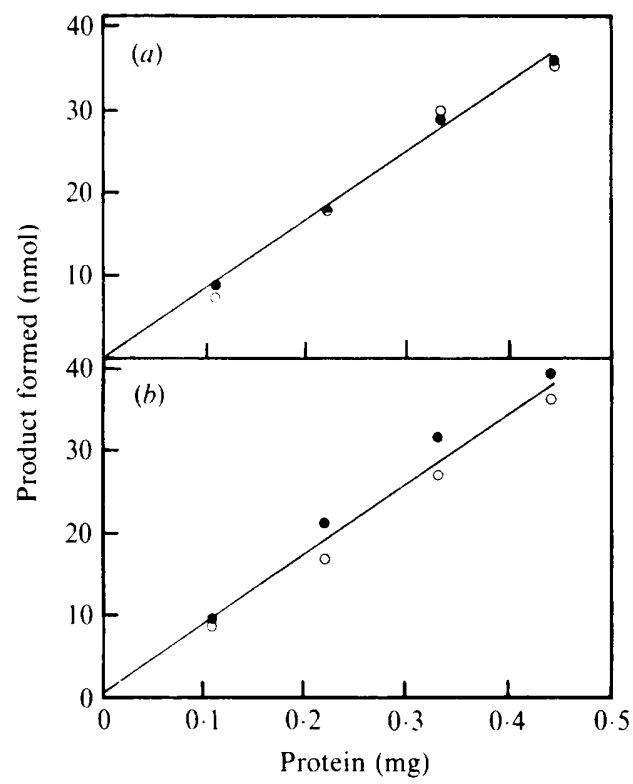

Fig. 1

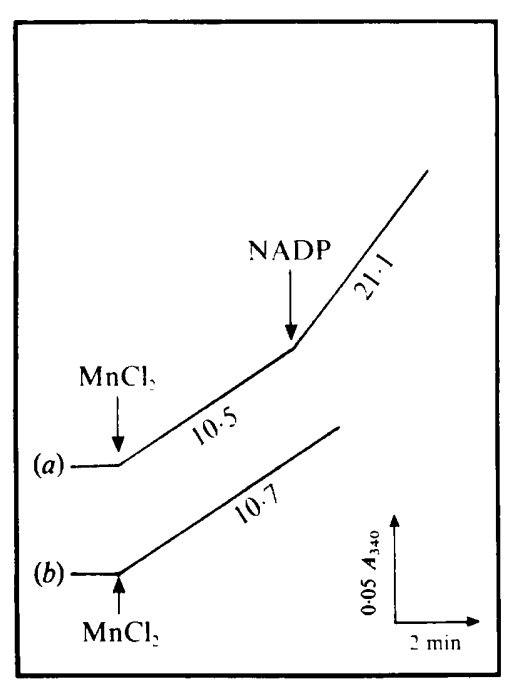

Fig. 2

Fig. 1. Comparison of pyridine nucleotide reduction and pyruvate formation by (a) NADP- and $(b)$ NAD-dependent malic enzymes of $B$. japonicum bacteroids. Pyridine nucleotide reduction was measured by following the increase in $A_{340}$. Reactions were stopped after 10 min and the concentration of pyruvate determined as described. $\mathrm{NADH}$ or $\mathrm{NADPH} ; \mathrm{O}$, pyruvate. The data are from one of duplicate experiments.

Fig. 2. Change in $A_{340}$ due to the reduction of $(a) \mathrm{NAD}^{+}$and $(b) \mathrm{NADP}^{+}$by malic enzymes of $B$. japonicum bacteroids. $\mathrm{MnCl}_{2}$ and $\mathrm{NADP}^{+}$were added to standard reaction mixtures (which contained NAD ${ }^{+}$) as indicated. The numbers on the traces give the nmol NAD(P)H formed $\min ^{-1}\left(\mathrm{mg}^{2}\right.$ protein $)^{-1}$. The data are from one of four replicate experiments.

\section{Table 1. NAD-ME, MDH and $O A A$ decarboxylation activities in $B$. japonicum bacteroid extracts}

$\mathrm{KCl}(10 \mathrm{mM})$ and $\mathrm{MnCl}_{2}(5 \mathrm{mM})$ were added to the standard reaction medium as indicated. ME activity was measured as $\mathrm{NAD}^{+}$reduction in the presence of malate, $\mathrm{MDH}$ as NADH oxidation in the presence of OAA, and OAA decarboxylation as pyruvate formation in the absence of malate and $\mathrm{NAD}^{+}$. The values are the means \pm standard errors of four determinations.

\begin{tabular}{lccc} 
& \multicolumn{3}{c}{ Activity [nmol min } \\
\cline { 2 - 4 } Assay conditions & NAD-ME & OAA decarboxylation & MDH \\
Crude extract & & & \\
$+\mathrm{KCl},-\mathrm{MnCl}_{2}$ & 0 & 0 & $\mathrm{ND}$ \\
$+\mathrm{KCl},+\mathrm{MnCl}_{2}$ & $11.9 \pm 0.6$ & 18.1 & $633 \pm 55$ \\
$-\mathrm{KCl},+\mathrm{MnCl}_{2}$ & $4.0 \pm 0.7$ & 16.5 & $633 \pm 55$ \\
Filtered extract* & & 38.7 & $566 \pm 16$ \\
$-\mathrm{KCl}+\mathrm{MnCl}_{2}$ & $4.2 \pm 0.6$ & &
\end{tabular}

ND, Not determined.

* Extract was passed through a Sephadex G-50 column prior to assay.

decarboxylation were not affected (results not shown). (5) Finally, we used $\left(\mathrm{NH}_{4}\right)_{2} \mathrm{SO}_{4}$ precipitation to partially separate the enzymes. The $\mathrm{MDH}$ activity of the extract was confined to the $50-70 \%\left(\mathrm{NH}_{4}\right)_{2} \mathrm{SO}_{4}$ fraction, whereas greater than $85 \%$ of the NAD- and NADP-ME activities were in the $30-50 \%$ fraction and less than $10 \%$ in the $50-70 \%$ fraction. These two 


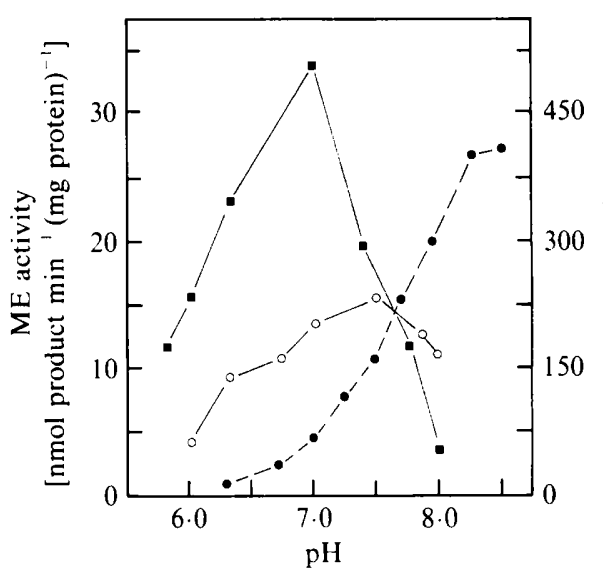

Fig. 3
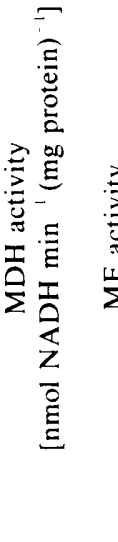

Fig. 3. Effect of pH on NAD- and NADP-dependent malic enzymes and NAD-dependent MDH of $B$. japonicum bacteroids. Activity of the 30-50\%( $\left.\mathrm{NH}_{4}\right)_{2} \mathrm{SO}_{4}$ fraction (ME) or 50-70\% $\left(\mathrm{NH}_{4}\right)_{2} \mathrm{SO}_{4}$ fraction (MDH) was measured using the standard reaction mixtures, except that a combination of $25 \mathrm{mM}-\mathrm{MES}$ and $25 \mathrm{mM}$-Tris buffers was used. MDH activity was assayed in the direction of malate oxidation. Each point is the mean of four determinations; the standard errors were $10 \%$ or less of the values. $\square$, NADdependent ME; O, NADP-dependent ME; O, NAD-dependent MDH.

Fig. 4. Effect of L-malate concentration on NAD- and NADP-dependent malic enzymes of $B$. japonicum bacteroids. Reaction mixtures were as described for the standard assay except that the concentration of L-malate was varied. NAD-dependent ME; O, NADP-dependent ME. The data are from one of duplicate experiments.

partially purified fractions were used to examine the effect of $\mathrm{pH}$ on $\mathrm{ME}$ and $\mathrm{MDH}$ activities. NAD-ME activity peaked at $\mathrm{pH} 7$, whereas NADP-ME was maximally active near $\mathrm{pH} 7 \cdot 5$ (Fig. $3)$. The $\mathrm{pH}$ profile of NAD-dependent $\mathrm{MDH}$ activity (measured as malate oxidation) was quite distinct from that of NAD-ME, reaching optimum activity at pH 8-8.5 (Fig. 3). Clearly, at $\mathrm{pH} 7$, there is no correlation between $\mathrm{MDH}$ and ME activities, and we therefore conclude that soybean bacteroids possess both an NAD- and an NADP-linked ME.

The two forms of ME could be distinguished by the marked difference in their response to increasing malate concentration (Fig. 4). The NAD-ME displayed typical hyperbolic kinetics, whereas activity of the NADP-dependent enzyme was inhibited at concentrations of malate greater than $2 \mathrm{mM}$. Kinetic constants of the enzymes were determined by fitting the data of Fig. 4 , together with those from a duplicate experiment with a different bacteroid extract, to the Michaelis-Menten equation as described by Duggleby (1981). The $K_{\mathrm{m}}$ for L-malate and the maximum velocity of NAD-ME were $1.9 \pm 0.4 \mathrm{mM}$ and $8.4 \pm 0.1 \mathrm{nmolmin}^{-1}\left(\mathrm{mg}^{2} \text { protein }\right)^{-1}$, respectively (means \pm standard error). The values of the corresponding parameters for NADPME (calculated from non-inhibitory concentrations of malate) were $0.10 \pm 0.01 \mathrm{~mm}$ and $10 \cdot 1 \pm 1 \cdot 1 \mathrm{nmolmin}-1$ (mg protein $)^{-1}$. Thus, the maximum velocity was similar for the two enzymes, but NADP-ME had an affinity for malate which was approximately 20 -fold greater than that of NAD-ME.

NAD- and NADP-ME were activated by ammonium ions. Activity of NAD-ME in extracts that had been extensively dialysed was stimulated approximately threefold when $10 \mathrm{mM}-\mathrm{NH}_{4} \mathrm{Cl}$ was added to the reaction mixtures, and fourfold when the concentration of $\mathrm{NH}_{4} \mathrm{Cl}$ was increased to $50 \mathrm{mM}$ (Table 2). NAD-ME was activated to some extent by $50 \mathrm{mM}-\mathrm{KCl}$ but not by $\mathrm{NaCl}$. NADP-dependent $\mathrm{ME}$ activity was stimulated $1 \cdot 7$ - and $2 \cdot 7$-fold by 10 and $20 \mathrm{mM}-\mathrm{NH}_{4} \mathrm{Cl}$, respectively, but $\mathrm{KCl}$ and $\mathrm{NaCl}$ had no effect (Table 2). Coenzyme $\mathrm{A}$, which is an activator of ME of plants (Macrae, 1971), did not stimulate either of the bacterial enzymes.

The activity of ME was compared to activities of certain TCA cycle enzymes and 3hydroxybutyrate dehydrogenase in the bacteroid extracts (Table 3). The NAD- and NADP-ME rates were somewhat less than isocitrate dehydrogenase and fumarase activities, but greater 
Table 2. Effect of salts on NAD- and NADP-dependent malic enzymes of B. japonicum bacteroids

The $30-50 \% \mathrm{NH}_{4}\left(\mathrm{SO}_{4}\right)_{2}$ fraction of the bacteroid extracts was dialysed for $2 \mathrm{~h}$ against 1000 vols $10 \mathrm{~mm}$ Tris/ $\mathrm{HCl}$ buffer ( $\mathrm{pH} 7)$. Activity was measured using the standard reaction mixture described, except that $\mathrm{KCl}$ was omitted. The values are the means \pm standard errors of four determinations.

\begin{tabular}{|c|c|c|}
\hline \multirow[b]{2}{*}{ Addition (mM) } & \multicolumn{2}{|c|}{ 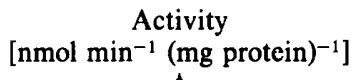 } \\
\hline & NAD-ME & NADP-ME \\
\hline $\begin{array}{l}\text { None } \\
\mathrm{KCl}(10) \\
\mathrm{KCl}(50) \\
\mathrm{NaCl}(10) \\
\mathrm{NaCl}(50) \\
\mathrm{NH}_{4} \mathrm{Cl}(10) \\
\mathrm{NH}_{4} \mathrm{Cl}(50)\end{array}$ & $\begin{array}{r}10.4 \pm 2 \cdot 0 \\
10.9 \pm 1 \cdot 7 \\
19 \cdot 3 \pm 0.4 \\
9.6 \pm 0.1 \\
9 \cdot 1 \pm 1 \cdot 3 \\
33 \cdot 2 \pm 3 \cdot 5 \\
44.3 \pm 4.6\end{array}$ & $\begin{array}{r}8.6 \pm 2.0 \\
9.3 \pm 1.0 \\
10.1 \pm 0.8 \\
9.5 \pm 0.5 \\
8.0 \pm 0.1 \\
15.0 \pm 3.9 \\
23.8 \pm 3.9\end{array}$ \\
\hline
\end{tabular}

Table 3. Activity of enzymes in the soluble extract of $B$. japonicum bacteroids

\section{Enzyme}

Malic enzyme (NAD) (EC 1.1.1.38)

Malic enzyme (NADP) (EC 1.1.1.40)

Pyruvate dehydrogenase (EC 1.2.4.1)

Isocitrate dehydrogenase (NADP) (EC 1.1.1.42)

Fumarase (EC 4.2.1.2)

Malate dehydrogenase (NAD) (EC 1.1.1.37) $\dagger$

Malate dehydrogenase (NADP) (EC 1.1.1.82) $\dagger$

3-Hydroxybutyrate dehydrogenase (EC 1.1.1.30)

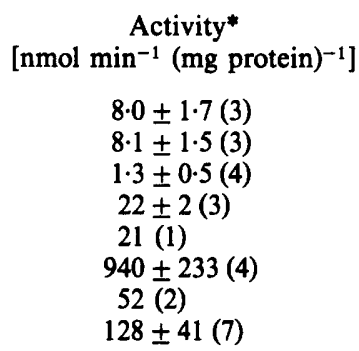

* The number of replicate extractions used to determine the activity \pm standard error is indicated in parenthesis.

$\dagger$ Assayed in the direction of OAA reduction: the oxidative activity of NAD-MDH at $\mathrm{pH} 7$ was $68 \pm 5 \mathrm{nmol}$ $\min ^{-1}$ (mg protein) $)^{-1}$.

Table 4. Oxidation of NADPH by sonicated B. japonicum bacteroids

Purified bacteroids were sonicated for three 1 min periods at $100 \mathrm{~W}$. The sonicate was centrifuged for $2 \mathrm{~min}$ at $14000 \mathrm{~g}$ and the supernatant assayed for $\mathrm{O}_{2}$ uptake as described by Day et al. (1986). The final concentrations of succinate and $\mathrm{NAD}(\mathrm{P}) \mathrm{H}$ in the reaction mixtures were $10 \mathrm{~mm}$ and $1 \mathrm{mM}$, respectively.

$\begin{array}{lc}\text { Substrate } & \begin{array}{c}\mathrm{O}_{2} \text { uptake } \\ \left.\text { Exmol } \mathrm{min}^{-1} \mathrm{ml}^{-1}\right)\end{array} \\ \text { Succinate } & \\ \text { NADH } & 179 \\ \text { NADPH } & 495 \\ \text { NADH + NADPH } & 14 \\ \text { Experiment 2 } & 495 \\ \text { Succinate } & \\ \text { NADH } & 165 \\ \text { NADPH } & 481 \\ & 12\end{array}$

than pyruvate dehydrogenase activity. Hydroxybutyrate dehydrogenase activity was substantially faster than ME and the TCA cycle enzyme activities. It is interesting to note that some TCA cycle dehydrogenases were NADP-linked and others NAD-linked (Table 3), yet only NADH was oxidized by sonic particles from bacteroids (Table 4). The rate of $\mathrm{O}_{2}$ uptake with NADH was similar to that with succinate, whereas with NADPH it was much slower. NADPH 
and NADH together gave the same rate as NADH alone (Table 4), suggesting that the oxidation of NADPH was catalysed by the NADH dehydrogenase.

\section{DISCUSSION}

The results demonstrate that $B$. japonicum bacteroids from soybean nodules possess both an NAD-linked and an NADP-linked ME. As malate or succinate are likely to be supplied to the bacteroid in vivo it seems reasonable to suggest that at least one of these malic enzymes is involved in organic acid oxidation during $\mathrm{N}_{2}$ fixation. The reported $\mathrm{O}_{2}$ :malate ratios of approximately 3 during malate-supported respiration of soybean bacteroids (Price et al., 1987), as well as the results of McKay et al. (1988), are indicative of ME involvement during aerobic metabolism. However, careful analysis of the products of malate oxidation under microaerobic conditions is required before a role in $\mathrm{N}_{2}$ fixation can be ascribed definitively to ME.

It could be argued that NAD-ME is more likely to function in $\mathrm{N}_{2}$ fixation, as it has a relatively low affinity for malate and would consequently only be active when ample substrate was available (e.g. from the plant cytosol). The higher affinity enzyme (i.e. NADP-ME) could be involved in 'maintenance' activities in the bacteroid. The results of Table 4 support these proposals; NADH was readily oxidized by sonicated bacteroids and therefore could contribute to ATP production in vivo. In contrast, NADPH was oxidized poorly by the electron transport chain of the bacteroids and hence is unlikely to be quantitatively important in energy production (assuming that a soluble transhydrogenase, which could transfer reducing equivalents from NADPH to NADH, is not active in $B$. japonicum). However, NADPH could be used to reduce nitrogenase (Dilworth \& Glenn, 1984).

Preliminary experiments with free-living $B$. japonicum strain USDA 110 indicate that NADME expression is stimulated by dicarboxylic acids (malate and succinate), whereas expression of NADP-ME is not (Quinnell \& Day, unpublished results). Stimulation of ME expression in $R$. leguminosarum by succinate has also been reported (McKay et al., 1988). This fits well with a role for NAD-ME in support of nitrogenase, since dicarboxylates are probably supplied to bacteroids during $\mathrm{N}_{2}$ fixation (Appleby, 1984; Dilworth \& Glenn, 1984). The stimulation of $\mathrm{ME}$ activity by $\mathrm{NH}_{4} \mathrm{Cl}$ would ensure maximum activity when ammonia concentrations are high, as occurs during nitrogen fixation. However, further work involving purification of the enzymes and identification of inducer metabolites in cultures of free-living $B$. japonicum is required to confirm this hypothesis.

ME may also be important in other aspects of the carbon metabolism of bacteroids and freeliving bacteria. In addition to supplying acetyl-CoA for the TCA cycle, ME could provide NADPH and pyruvate for various biosynthetic pathways. Our results suggest that NADP-ME is more likely to have such a role.

The award of an ANU-Alexander von Humboldt visiting fellowship to L. Copeland is acknowledged.

\section{REFER ENCES}

APPLEBY, C. A. (1984). Leghemoglobin and Rhizobium respiration. Annual Review of Plant Physiology 35, 443-478.

ARWas, R., MCKay, 1. A., Rowney, F. R. P., Dilworth, M. J. \& Glenn, A. R. (1985). Properties of organic acid utilization mutants of Rhizobium leguminosarum strain 300. Journal of General Microbiology 131, 2059-2066.

Day, D. A. \& Hanson, J. B. (1977). Pyruvate and malate transport and oxidation in corn mitochondria. Plant Physiology 59, 630-635.

Day, D. A., Price, G. D. \& Gresshoff, P. M. (1986). Isolation and oxidative properties of mitochondria and bacteroids from soybean root nodules. Protoplasma 134, 121-129.

Day, D. A., Price, G. D., Schuller, K. A. \&
Gresshoff, P. M. (1987). Nodule physiology of a supernodulating soybean (Glycine max) mutant. Australian Journal of Plant Physiology 14, 527-538.

Dilworth, M. \& GlenN, A. (1984). How does a legume nodule work? Trends in Biochemical Sciences 9, 519-523.

DugGlebY, R. G. (1981). A nonlinear regression program for small computers. Analytical Biochemistry 110, 9-18.

FinaN, T. M., WoOd, J. M. \& Jordan, D. C. (1981). Succinate transport in Rhizobium leguminosarum. Journal of Bacteriology 148, 193-202.

HANSEN, E. J. \& JUNI, E. (1975). Isolation of mutants of Escherichia coli lacking NAD- and NADP-linked malic enzyme activities. Biochemical and Biophysical Research Communications 65, 559-566. 
KarR, D. B., Waters, J. K., Suzuki, F. \& EMERICH, D. W. (1984). Enzymes of the poly- $\beta$-hydroxybutyrate and citric acid cycles of Rhizobium japonicum bacteroids. Plant Physiology 75, 1158-1162.

McKay, I. A., GlenN, A. R. \& Dilworth, M. J. (1985). Gluconeogenesis in Rhizobium leguminosarum. Journal of General Microbiology 131, 2067-2073.

McKay, I. A., Dilworth, M. J. \& GlenN, A. R. (1988). $C_{4}$-dicarboxylate metabolism in free-living and bacteroid forms of Rhizobium leguminosarum MNF 3481. Journal of General Microbiology 134, 1433-1440.

MACraE, A. R. (1971). Isolation and properties of a 'malic' enzyme from caulifiower bud mitochondria. Biochemical Journal 122, 495-501.

Murai, T., Tokushige, M., Nagai, J. \& Katsuki, H. (1971). Physiological functions of NAD- and NADP-linked malic enzymes in Escherichia coli. Biochemical and Biophysical Research Communications 43, 875-881.

Price, G. D., Day, D. A. \& Gresshoff, P. M. (1987). Rapid isolation of intact peribacteroid envelopes from soybean nodules and demonstration of selective permeability to metabolites. Journal of Plant Physio$\log y$ 130, $157-164$.
Ronson, C. W., Lyttleton, P. \& Robertson, J. G. (1981). $C_{4}$-dicarboxylate transport mutants of Rhizobium trifolii form ineffective nodules on Trifolium repens. Proceedings of the National Academy of Sciences of the United States of America 78, 4284-4288.

Salminen, S. O. \& Streeter, J. G. (1987). Involvement of glutamate in the respiratory metabolism of Bradyrhizobium japonicum bacteroids. Journal of Bacteriology 169, 495-499.

Storvall, I. \& Cole, M. (1978). Organic acid metabolism by isolated Rhizobium japonicum bacteroids. Plant Physiology 61, 787-790.

STUMPF, D. K. \& BURRIS, R. H. (1979). A micromethod for the purification and quantification of organic acids of the tricarboxylic acid cycle in plant tissues. Analytical Biochemistry 95, 311-315.

Udvardi, M. K., Price, G. D., Gresshoff, P. M. \& DAY, D. A. (1988). A dicarboxylate transporter on the peribacteroid membrane of soybean nodules. FEBS Letters 231, 36-40.

Wedding, R. T., Black, M. K. \& PaP, D. (1976). Malate dehydrogenase and malic enzyme in the oxidation of malate by sweet potato mitochondria. Plant Physiology 58, 740-743. 